\title{
PENYULUHAN TENTANG KANKER SERVIK MEMPENGARUHI PENGETAHUAN DAN MOTIVASI PEMERIKSAAN IVA PADA WANITA USIA SUBUR (WUS)
}

\author{
Jumaida ${ }^{1}$, Sunarsih ${ }^{2}$, Rosmiyati ${ }^{3}$ \\ 1Program Studi DIV Kebidanan Fakultas Kedokteran Universitas Malahayati \\ Email: jumaida159@gmail.com \\ 2Dosen Program Studi DIV Kebidanan Universitas Malahayati \\ Email: sunarsih@malahayati.ac.id \\ 3Dosen Program Studi DIV Kebidanan Universitas Malahayati \\ Email: rosmiyati@malahayati.ac.id
}

\begin{abstract}
Background The incidence of cervical cancer can be prevented by early detection of precancerous lesions. Data obtained in TanjungBintang Health Center in TanjungBintang District in September - December 2018, of 430 women of childbearing age who had pap smears and IVA, 2 people $(0.46 \%)$ detected stage $1 \mathrm{~b}$ uterine cancer, 57 people (13.4 \%) experienced pre-cervical cancer lesions.

Purpose The aim of the study was to determine the effect of counseling on cervical cancer on the knowledge and motivation of IVA examination on wus in the tanjungbintang health center in TanjungBintang district, South Lampung Regency in 2019

Methode This type of research is quantitative, with a Quasi Experiment design. The population of this study were all women of childbearing age totaling 11,361 with a sample of 39 people, taking purposive sampling. The objects in this research are knowledge, morivation and knowledge using primary data directly from respondents. The research was conducted on May 20 - June 21, 2019 in the TanjungBintang Health Center District, TanjungBintang District, South Lampung Regency. Data collection using a questionnaire.

The results of the study The average maternal knowledge before counseling was 10.28 with a standard deviation of 2.224 and after counseling was 17.41 with a standard deviation of 1.773. The average maternal motivation before counseling was 43.59 with a standard deviation of 7.556 and after counseling was 62.26 with a standard deviation of 6.142 .

ConclusionThere is an effect of counseling on cervical cancer on knowledge ( $p$-value $=0,000$ ( $p$-value $<\alpha=0.05)$ and motivation ( $p$-value $=0,000)$ at WUS.

Suggestions are more to improve skills to officers in the field about extension techniques, and provide facilities for counseling that are more adequate to increase motivation for women of childbearing age..
\end{abstract}

Keywords: cervical cancer, knowledge, motivation, counseling

\section{ABSTRAK}

Latar Belakang Kejadian kanker serviks dapat dicegah dengan deteksi dini lesi prakanker. Data yang didapat di Wilayah Puskesmas Tanjung Bintang Kecamatan Tanjung Bintang bulan september - desember 2018, dari 430 wanita usia subur yang melakukan pap smear dan IVA, sebanyak 2 orang $(0,46 \%)$ terdeteksi kanker rahim stadium $1 b, 57$ orang $(13,4 \%)$ mengalami lesi pra kanker serviks.

Tujuan penelitian diketahui pengaruh penyuluhan tentang kanker servik terhadap pengetahuan dan motivasi pemeriksaan IVA pada wus di wilayah puskesmas tanjung bintang kecamatan tanjung bintang kabupaten lampung selatan tahun 2019

Metode Jenis penelitian kuantitatif, dengan rancangan Quasi Eksperimen. Populasi penelitian ini seluruh Wanita usia subur berjumlah 11.361 dengan sampel sebanyak 39 orang, pengambilan sampel purposive sampling. Objek dalam penelitian ini pengetahuan, morivasi dan pengetahuan menggunakan data primer langsung dari responden. Penelitian telah dilakukan pada tanggal 20 Mei - 21 Juni 2019 di Wilayah Puskesmas Tanjung Bintang Kecamatan Tanjung Bintang Kabupaten Lampung Selatan. Pengumpulan data menggunakan kuesioner.

Hasil penelitian Rata-rata pengetahuan ibu sebelum penyuluhan adalah 10,28 dengan standar deviasi 2,224 dan setelah penyuluhan adalah 17,41 dengan standar deviasi 1,773. Rata-rata motivasi ibu sebelum 
penyuluhan adalah 43,59 dengan standar deviasi 7,556 dan setelah penyuluhan adalah 62,26 dengan standar deviasi 6,142.

Kesimpulan Ada Pengaruh penyuluhan tentang kanker servik terhadap Pengetahuan ( $p$-value $=0,000$ ( $p$-value $<\alpha=0,05)$ dan Motivasi $(p$-value $=0,000)$ pada WUS

Saran lebih meningkatkan ketrampilan kepada petugas dilapangan tentang teknik penyuluhan, serta memberikan fasilitas untuk penyuluhan yang lebih memadai hingga dapat meningkatkan motivasi kepada wanita usia subur

Kata kunci: kanker servik, pengetahuan, motivasi, penyuluhan

\section{PENDAHULUAN}

Kesehatan reproduksi adalah adalah keadaan sehat secara fisik, mental, sosial, secara utuh tidak semata-mata bebas dari penyakit atau kecacatan yang berkaitan dengan system, fungsi dan proses reproduksi (Peraturan Pemerintah RI No 61, 2014) Menjaga kesehatan organ reproduksi pada wanita adalah sangat penting karena terdapat organ yang kompleks sehingga dapat timbul bermacam penyakit yang berbahaya seperti kanker serviks, Kanker serviks adalah tumor ganas yang tumbuh di daerah leher rahim (serviks). Kanker serviks merupakan keganasan yang paling banyak ditemukan di berkembang begitu juga di Indonesia menduduki peringkat 1 . Umumnya kanker serviks sekitar $70 \%$ datang dengan kondisi stadium lanjut (Mayrita, 2015)

Kejadian kanker serviksdapat dicegah dengan deteksi dini lesi prakanker. Kegiatan deteksi dini kanker leher rahim dilakukan dengan metode Inspeksi Visual dengan Asam Asetat (IVA), pemeriksaan IVA bertujuan untuk menemukan lesi pra kanker leher rahim, sebelum menjadi kanker. Metode inspeksi visual lebih mudah, lebih sederhana dan lebih mampu laksana. Metode ini dapat dilakukan di semua tingkat pelayanan kesehatan oleh petugas kesehatan yang terlatih (Kemenkes, 2015). Skrining IVA efektif memberikan kontribusi untuk menurunkan mortalitas dan morbiditas yang terkait dengan keganasan kanker serviks (Apriningrum, 2017).

Kanker serviks merupakan kanker paling sering keempat pada wanita dengan perkiraan 530.000 kasus baru, yang mewakili $7,9 \%$ dari semua kanker wanita. Pada tahun 2015 sekitar 90\% kematian atau sebanyak 270.000 akibat kanker serviks terjadi di negara berpenghasilan rendah dan menengah (World Health Organization, 2017). Perkiraan American Cancer Society untuk kanker serviks di Amerika Serikat untuk tahun 2018 adalah sekitar 13.240 kasus baru kanker serviks invasif.Sekitar 4.170 wanita akan meninggal akibat kanker serviks (American Cancer Society, Januari 2018).Pada tahun 2018, diperkirakan 930 kasus baru kanker serviks akan didiagnosis di Australia (Australian Institute of Health and Welfare, Januari 2018). Di Hongkong, kanker serviks adalah kanker ketujuh yang paling umum di antara wanita dengan 500 kasus baru di tahun 2015, menyumbang 3,3\% dari semua kasus kanker baru pada wanita (Kemenkes, 2016).

Penyakit kanker serviks merupakan penyakit kanker dengan prevalensi tertinggi di Indonesia pada tahun 2013, yaitu kanker serviks sebesar 0,8\% Provinsi Kepulauan Riau, Provinsi Maluku Utara dan Provinsi D.I. Yogyakarta memiliki prevalensi kanker serviks tertinggi yaitu sebesar 1,5\%. Berdasarkan estimasi jumlah penderita kanker serviksterbanyak terdapat pada Provinsi Jawa Timur dan Provinsi Jawa Tengah, sedangkan di Provinsi Lampung sebesar $0,2 \%$ atau sebanyak 765 orang (Kemenkes, 2015). Tahun 2016 dari 1.739 jumlah WUS yang dicurigai Kanker serviks, provinsi Lampung merupakan urutan ketiga tertinggi dengan jumlah 227 kasus setelah DKI Jakarta (269 kasus) dan Bali sebanyak 254 kasus (Kemenkes, 2017)

Berdasarkan laporan dari 25 rumah sakit dengan jumlah penderita kanker berkunjung dan dirawat di rumah sakit di Provinsi Lampung selama tahun 2016, dari 1.210.947 perempuan usia 30-49 tahun, sebanyak $28.612(2,36 \%)$ perempuan yang melakukan pemeriksaan IVA, Kabupaten tertinggi ada di Bandar Lampung sebanyak $11.459(8,02)$ orang dan terendah di lampung Selatan sebanyak $171(0,09 \%)$. Pada tahun 2017, dari 1.330 .342 perempuan usia 30-49 tahun yang melakukan pemeriksaan IVA sebanyak 430 WUS dengan IVA positif dimana kasus positif IVA berada di Kabupaten Lampung Selatan, dari 3210 wanita yang melakukan pemeriksaan IVA sebanyak 63 orang dinyatakan positif (Dinas Kesehatan Provinsi Lampung, 2018).

Berdasarkan data Kabupaten Lampung Selatan diketahui data tahun 2016, dari bulan Januari sampai dengan Juli diketahui bahwa wilayah Kerja Puskesmas yang aktif melakukan pendeteksian dini ca serviks adalah 
PuskesmasKalianda sebanyak 133 orang, Puskesmas Sidomulyo sebanyak 126 orang dan Puskesmas hajimena sebanyak100 sedangkan Puskesmas Tanjung Bintang salah satu Puskesmas yang sedikit melakukan pemeriksaan IVA yaitu sebanyak 36 orang namun memiliki kejadian tertinggi IVA Positif yaitu sebesar 8,33\% (Dinkes Lampung Selatan, 2017).

Data yang didapat di Wilayah Puskesmas Tanjung Bintang Kecamatan Tanjung Bintang bulan september - desember 2018, dari 430 wanita usia subur yang melakukan pap smear dan IVA, sebanyak 2 orang $(0,46 \%)$ terdeteksi kanker rahim stadium 1b, 57 orang $(13,4 \%)$ mengalami lesi pra kanker serviks yang ditandai dengan adanya peradangan, keputihan, warna kemerahan pada mulut rahim, ada benjolan di mulut rahim dan sisanya dengan kondisi normal.

Kejadian kanker serviks dapat dicegah dengan deteksi dini lesi prakanker. Deteksi dini lesi prakanker dapat mencegah lesi prakanker tidak berlanjut menjadi kanker leher rahim jika segera dilakukan pengobatan. Hal ini terbukti di negaranegara maju yang telah mengalami penurunan insiden kanker serviks. Contohnya di Amerika Serikat, dalam 50 tahun terakhir insidens kanker serviks turun sekitar $70 \%$ yang dimungkinkan karena adanya program deteksi dini dan tatalaksana yang baik. Hal ini sejalan pula dengan penelitian Peirson (2013), yang menjalani systematic review dari tahun 1995 sampai 2012. Hasil penelitian membuktikan bahwa deteksi dini lesi prakanker dapat menurunkan insiden kanker serviks dan menurunkan angka kematian yang disebabkan oleh kanker serviks.

Penelitian membuktikan bahwa tes IVA memiliki tingkat sensitivitas dan spesifisitas yang cukup tinggi untuk digunakan sebagai metode penapisan lesi prakanker. Hasil penelitian Wiyono dalam Mulyati (2015), di Semarang pada 120 wanita usia subur menunjukkan hasil sensitivitas tes IVA adalah $84 \%$ dan spesifisitas $89 \%$. Hal ini sesuai pula dengan penelitian Arbyn (2014) pada 58.000 wanita di India dan Afrika dengan hasil penelitian yang menunjukkan sensitivitas tes IVA adalah $83 \%$ dan spesifisitas tes IVA adalah $85 \%$.

Banyak faktor yang berhubungan dengan keikutsertaan ibu untuk ikut serta pada tes IVA di antaranya adalah faktor perilaku yang dipengaruhi oleh pengetahuan, niat dan sikap ibu. Wanita yang bersikap baik berpotensi lebih besar menjalani pemeriksaan IVA jika dibandingkan dengan wanita yang bersikap kurang baik. Hasil penelitian menunjukkan bahwa persepsi yang salah (seperti tidak perlu memeriksakan diri karena tidak adanya gejala kanker, deteksi dini kanker serviks hanya untuk wanita yang berperilaku seksual yang tidak aman) dapat mempengaruhi keikutsertaan deteksi dini kanker serviks. Menurut Mulyati (2015) partisipasi wanita untuk pemeriksaan Inspeksi Visual Asam Asetat (IVA) masih minim, akibatnya mayoritas untuk mengetahui setelah stadium tinggi sehingga peluang kesembuhannya makin kecil.

Salah satu upaya untuk menciptakan perilaku masyarakat yang kondusif untuk kesehatan adalah melalui pendidikan kesehatan yaitu kegiatan untuk meningkatkan pengetahuan, sikap dan perilaku masyarakat. Selain itu status ekonomi juga berpengaruh terhadap rendahnya deteksi dini kanker servik. Penyebaran masalah kesehatan yang berbeda berdasarkan status ekonomi pada umumnya dipengaruhi oleh adanya perbedaan kemampuan ekonomi dalam mencegah penyakit dan adanya perbedaan sikap hidup dan prilaku yang dimiliki seseorang (Notoadmotjo, 2012).

Keikutsertaan pemeriksaan IVA suatu bentuk perilaku yang disebabkan oleh berbagai hal antara lain karena faktor predisposisi (pengetahuan, sikap, dan lain-lain), pemungkin dan penguat (Notoadmotjo, 2012). Peningkatan pengetahuan wanita usia subur (WUS), merupakan tanggungjawab dari petugas kesehatan, banyak cara yang dapat dilakukan untuk meningkatkan pengetahuan salah satunya dengan memberikan penyuluhan. Penelitian Andari (2014) Hasil dari penelitian ini menujukkan terdapat pengaruh pendidikan kesehatan dengan model Peer Group terhadap perilaku Ibu melakukan Deteksi Dini Kanker Serviks antara kelompok eksperimen dengan kelompok kontrol.

Berdasarkan hasil prasurvey yang dilakukan dengan wawancara tidak terstruktur yang dilakukan peneliti tanggal 04-05 Januari 2019 terhadap 20 wanita usia subur (WUS) yang ada di wilayah Puskesmas, diketahui bahwa seluruh WUS tersebut belum pernah ada yang melakukan pemeriksaan IVA / pap smear, sebanyak 8 (40\%) orang tahu tentang pemeriksaan IVA / pap smear dan $12(60 \%)$ orang tidak mengetahui tentang pemeriksaan IVA / pap smear. Dari $20(100 \%)$ WUS tersebut belum ada satupun yang melakukan pemeriksaan IVA / pap smear. Menurut hasil wawancara dengan ke $20(100 \%)$ WUS tersebut, terungkap bahwa petugas kesehatan pernah memberikan penyuluhan tentang IVA/ pap smearnamun sudah lama dan tidak pernah ada lagi penyuluhan berkaitan dengan kanker serviks namun petugas kesehatan pernah menganjurkan WUS untuk melakukan pemeriksaan IVA pap smear. 
Berdasarkan paparan di atas, maka penulis tertarik untuk meneliti tentang. Pengaruh Penyuluhan Tentang Kanker ServikTerhadap Pengetahuan Dan Motivasi Pemeriksaan IVA Pada WUS Di Wilayah Puskesmas Tanjung Bintang Kecamatan Tanjung Bintang Kabupaten Lampung Selatan Tahun 2019.

\section{METODE PENELITIAN}

Jenis penelitian yang digunakan dalam penelitian ini adalah penelitian kuantitatif dan rancangan penelitian yang digunakan adalah rancangan penelitian quasi eksperimen atau eksperimen semu dengan one group pretestpostest dimana peneliti melakukan observasi pertama (pretes) kemudian peneliti menguji perubahan perubahan yang terjadi setelah adanya perlakuan.
Populasi pada penelitian ini adalah wanita usia subur yang ada diWilayah Puskesmas Tanjung Bintang kecamatan tanjung bintang bulan Januari 2019 sebanyak 11.361 orang. Sampel dalam penelitian ini menggunakan metode purposive sampling sebanyak 39 responden

\section{HASIL}

Karakteristik Responden

Berdasarkan tabel 1 diketahui bahwa usia terbanyak yang mengikuti penyuluhan adalah usia 25-30 tahun yaitu sebanyak 15 orang $(38,4 \%)$, pendidikan terbanyak adalah tamatan SMP yaitu sebanyak 19 orang $(48,6 \%)$, Jumlah anak yang terbanyak adalah 2 anak yaitu sebanyak 17 orang $(43,6 \%)$ dan pekerjaan yang terbanyak adalah ibu rumah tangga yaitu sebanyak 31 orang $(79,7 \%)$.

Tabel 1 Distribusi Frekuensi Karakteristik Responden

\begin{tabular}{clcc}
\hline Variabel & Kategori & Jumlah & Persentase \\
\hline Usia & $25-30$ & 15 & 38,4 \\
& $31-35$ & 9 & 23,1 \\
& $36-40$ & 10 & 25,6 \\
\multirow{5}{*}{ Pendidikan } & $41-45$ & 5 & 12,9 \\
& SD & 5 & 12,9 \\
& SMP & 19 & 48,6 \\
& SMA & 14 & 35,9 \\
& SARJANA & 1 & 2,6 \\
\multirow{5}{*}{ Pekerjaan / Jumlah Anak } & 1 & 6 & 15.4 \\
& 2 & 17 & 43.6 \\
& 3 & 14 & 35,9 \\
& 4 & 2 & 5.1 \\
& IRT & 31 & 79.4 \\
& P. Swasta & 3 & 7.7 \\
& Wiraswasta & 5 & 12.9 \\
\hline \multicolumn{6}{c}{} & 39 & 100.0 \\
\hline
\end{tabular}

\section{Analisis Univariat}

Berdasarkan tabel 2 pengetahuan sebelum penyuluhan tentang kanker serviks, berdasarkan hasil olah data yang dilakukan, diperoleh rataratapengetahuan ibu sebelum penyuluhan adalah 10,28 dengan standar deviasi 2,224.

Tabel 2 Rata-Rata pengetahuan sebelum dilakukan penyuluhan Di Wilayah Puskesmas Tanjung Bintang Kecamatan Tanjung Bintang Kabupaten Lampung Selatan Tahun 2019

\begin{tabular}{cccccc}
\hline Pengetahuan & Mean & SD & Min & Max & N \\
\hline Sebelum Penyuluhan & 10,28 & 2,224 & 6 & 14 & 39 \\
\hline
\end{tabular}

Tabel 3 Rata-rata pengetahuan setelah dilakukan penyuluhan Di Wilayah Puskesmas Tanjung Bintang Kecamatan Tanjung Bintang Kabupaten Lampung Selatan Tahun 2019

\begin{tabular}{rccccc}
\hline Pengetahuan & Mean & SD & Min & Max & N \\
\hline Setelah penyuluhan & 17,41 & 1,773 & 14 & 20 & 39 \\
\hline
\end{tabular}


Berdasarkan tabel 3 menunjukkan bahwa setelahpenyuluhan tentang kanker, berdasarkan hasil olah data yang dilakukan, diperoleh rata-rata 17,41 dengan standar deviasi1,773.
Berdasarkan tabel 4 sebelum penyuluhan tentang kanker serviks, berdasarkan hasil olah data yang dilakukan, diperoleh rata-ratamotivasi ibu sebelum penyuluhan adalah 43,59 dengan standar deviasi 7,556

Tabel 4 Rata-ratamotivasi keikutsertaan wanita usia subur untuk melakukan pemeriksaan Inspeksi Visual Asam Asetat (IVA) sebelumdilakukan penyuluhan Di Wilayah Puskesmas Tanjung Bintang Kecamatan Tanjung Bintang Kabupaten Lampung Selatan Tahun 2019

\begin{tabular}{cccccc}
\hline Motivasi & Mean & SD & Min & Max & N \\
\hline Sebelum Penyuluhan & 43,59 & 7,556 & 28 & 56 & 39 \\
\hline
\end{tabular}

Tabel 5 Rata-ratamotivasi keikutsertaan wanita usia subur untuk melakukan pemeriksaan Inspeksi Visual Asam Asetat (IVA) setelah dilakukan penyuluhan di Wilayah Puskesmas Tanjung Bintang Kecamatan Tanjung Bintang Kabupaten Lampung Selatan Tahun 2019

\begin{tabular}{cccccc}
\hline Motivasi & Mean & SD & Min & Max & N \\
\hline Setelah penyuluhan & 62,26 & 6,142 & 52 & 72 & 39 \\
\hline
\end{tabular}

Berdasarkan tabel 5 menunjukkan bahwa setelahpenyuluhan tentang kanker, berdasarkan hasil olah data yang dilakukan, diperoleh rata-rata 62,26 dengan standar deviasi 6,142.

\section{Analisis Bivariat}

Berdasarkan tabel 6 diatas, hasil uji statistik didapatkan $t$-tess $>t$ tabel, 25,013>1,780pvalue $=0,000$ ( $p$-value $<a=0,05)$ yang berarti ada
Pengaruh penyuluhan tentang kanker servikterhadap Pengetahuan WUSdi Wilayah Puskesmas Tanjung BintangKecamatan Tanjung Bintang Kabupaten Lampung Selatan Tahun 2019.Berdasarkan hasil terlihat bahwa, pada kelompok setelah diberikan penyuluhan memiliki kenaikan tingkat pengetahuan dengan selisih 7,128 poin.

Tabel 6 Pengaruh penyuluhan tentang kanker servikterhadap Pengetahuan pada WUS di Wilayah Puskesmas Tanjung Bintang Kecamatan Tanjung Bintang Kabupaten Lampung Selatan Tahun 2019

\begin{tabular}{ccccccc}
\hline Kelompok & N & Beda Mean & SD & t-test & P-Value & Keterangan \\
\hline $\begin{array}{c}\text { Pengetahuan sebelum - } \\
\text { setelah penyuluhan }\end{array}$ & 39 & 7,128 & 1,780 & 25,013 & 0,000 & Ada pengaruh \\
\hline
\end{tabular}

Tabel 7 Pengaruh penyuluhan tentang kanker servikterhadap Motivasi Pemeriksaan IVA pada WUS di Wilayah Puskesmas Tanjung Bintang Kecamatan Tanjung Bintang Kabupaten Lampung Selatan Tahun 2019

\begin{tabular}{ccccccc}
\hline Kelompok & $\mathrm{N}$ & Mean & SD & t-test & P-Value & Keterangan \\
\hline $\begin{array}{c}\text { Motivasi sebelum - setelah } \\
\text { penyuluhan }\end{array}$ & 39 & 18,667 & 8,122 & 14,353 & 0,000 & Ada pengearuh \\
\hline
\end{tabular}

Berdasarkan hasil analisis uji bivariat pada table 7 diatas, hasil uji statistik didapatkan $\mathrm{t}$-tes $>\mathrm{t}$ tabel, 14,353> 8,122, $p$-value $=0,000$ ( $p$-value $<a=$ 0,05 ) yang berarti ada Pengaruh penyuluhan tentang kanker servikterhadap Motivasi Pemeriksaan IVA pada WUS di Wilayah Puskesmas Tanjung Bintang Kecamatan Tanjung Bintang Kabupaten Lampung Selatan Tahun 2019.Berdasarkan hasil terlihat bahwa, pada kelompok yang diberikan penyuluhan memiliki kenaikan motivasi yang tinggi dibandingkan dengan kelompok yang tidak diberikan penyuluhan dengan selisih 18,667 poin.

\section{PEMBAHASAN}

Analisa univariat

Pengetahuan kanker servik pada wanita usia subur sebelum penyuluhan 
Dari hasil penelitian rata-ratapengetahuan ibu sebelum penyuluhan adalah 10,28 dengan standar deviasi 2,224.

Sejalan dengan teori Notoadmotjo (2012) sebagian besar pengetahuan manusia diperoleh melalui mata dan telinga. Pengetahuan itu sendiri dipengaruhi oleh faktor pendidikan formal. Tetapi tidak berarti seseorang yang berpendidikan rendah mutlak berpengetahuan rendah pula. Mengingat peningkatan pengetahuan tidak mutlak diperoleh dari pendidikan formal saja, tetapi dapat diperoleh melalui pendidikan non formal.

Sejalan dengan penelitian yang dilakukan olehNingrum (2012) dengan Faktor-Faktor Yang Mempengaruhi Pengetahuan Ibumengikuti Deteksi Dini Kanker Serviks Melalui Metode Inspeksi Visual Asam Asetat (Iva) Di Kabupaten Banyumas. Hasil pengetahuan yang tinggi di sebagian besar (49, 5\%).. Penelitian yang dilakukan Sepa (2015) dengan judul Pengaruh Penyuluhan Kanker Serviks Terhadap Minat Pemeriksaan IVA Pada Ibu Usia 20-60 Tahun Di Dusun Ngangkrik Triharjo SlemanTahun 2015, diperoleh hasil sebelum penyuluhan minat pemeriksaan IVA dalam kategori kurang.

Berdasarkan hasil penelitian diketahui sebelum dilakukan penyuluhan terlihat pengetahuan yang kurang terhadap Kanker Servik dimana ratarata pengetahuan sebesar 10,28 point, nilai terendah sebesar 6 point dan nilai tertinggi sebesar 14 point. Pengetahuan dapat berfungsi sebagai pendorong. Setiap orang mempunyai pengetahuan untuk melakukan Kanker Servik , baik itu pengetahuan dari dalam diri maupun dari luar dirinya. WUS akan bersungguh-sungguh jika memiliki pengetahuan yang tinggi. Pengetahuan seorang akan turut menentukan pengetahuan seseorang terhadap Kanker Servik .

Pengetahuan kanker serviks pada wanita usia subur setelah penyuluhan

Berdasarkan hasil penelitian Setelahpenyuluhan tentang kanker, berdasarkan hasil olah data yang dilakukan, diperoleh rata-rata 17,41 dengan standar deviasi1,773.

Sejalan dengan teori menurut Syafrudin (2011) penyuluhan kesehatan merupakan kegiatan pendidikan yang dilakuakn dengan cara menyebarkan pesan, menanamkan keyakinan, sehingga masyarakat tidak saja sadar, tahu dan mengerti, tetapi juga mau dan bisa melakukan mutu anjuran yang ada hubungannya dengan kesehatan. Banyak jenis yang mempengaruhi seseorang tetapi dapat digolongkan menjadi dua golongan yaitu faktor internal dan faktor eksternal (Mubarak, 2012).
Sejalan dengan penelitian yang dilakukan olehSepa (2015) dengan judul Pengaruh Penyuluhan Kanker Serviks Terhadap Minat Pemeriksaan IVA Pada Ibu Usia 20-60 Tahun Di Dusun Ngangkrik Triharjo SlemanTahun 2015, diperoleh hasil setelah penyuluhan diberikan minat dalam kategori baik. Hasil penelitian ini mendukung penelitian dari Latifah (2010) yang menunjukkan bahwa ada hubungan antara pengetahuan tentang kanker serviks dengan sikap deteksi dini kanker serviks. Dari uraian diatas dapat disimpulkan bahwa tingkat pengetahuan yang tinggi belum menjamin seseorang untuk memiliki perilaku yang baik.

Menurut pendapat peneliti, pengetahuan yang dimiliki seseorang akan suatu penyakit, secara tidak langsung akan mempengaruhi seseorang tersebut untuk melakukan pencegahan. Setiap orang mempunyai pengetahuan, baik itu pengetahuan dari dalam diri maupun dari luar dirinya. Wanita Usia Subur (WUS) melakukan Kanker Servik dengan sungguh-sungguh jika memiliki pengetahuan yang tinggi. Sehingga dengan adanya pengetahuan dapat menimbulkan pengetahuan dari seseorang untuk melakukan sesuatu sesuai dengan pengetahuan yang dimilikinya.

Motivasi keikutsertaan wanita usia subur untuk melakukan pemeriksaan Inspeksi Visual Asam Asetat (IVA) sebelumdilakukan penyuluhan

Berdasarkan hasil penelitian motivasi ibu sebelum penyuluhan adalah 43,59 dengan standar deviasi 7,556 .

Menurut Nursalam (2016), mengatakan bahwa motivasi adalah Suatu keahlian dalam mengarahkan seseorang agar mau melakukan sesuatu secara berhasil, sehingga keinginan seseorang tercapai. Pentingnya Motivasi karena Motivasi adalah hal yang menyebabkan, menyalurkan dan mendukung perilaku manusia, supaya mau bekerja giat dan antusias untuk mencapai hasil yang optimal.

Sejalan dengan penelitian yang dilakukan olehNingrum (2012) dengan Faktor-Faktor Yang Mempengaruhi Motivasi Ibumengikuti Deteksi Dini Kanker Serviks Melalui Metode Inspeksi Visual Asam Asetat (Iva) Di Kabupaten Banyumas. Hasil motivasi yang tinggi di sebagian besar (49, 5\%). Pengetahuan influrnced motivasi ibu untuk mengikuti deteksi dini kanker serviks melalui IVA ( $p$ $=0,000)$. Penelitian yang dilakukan Sepa (2015) dengan judul Pengaruh Penyuluhan Kanker Serviks Terhadap Minat Pemeriksaan IVA Pada Ibu Usia 20-60 Tahun Di Dusun Ngangkrik Triharjo SlemanTahun 2015, diperoleh hasil sebelum 
penyuluhan minat pemeriksaan IVA dalam kategori kurang.

Menurut peneliti penyuluhan merupakan upaya persuasi atau pembelajaran kepada masyarakat mau melakukan tindakan (praktik) untuk memelihara (mengatasi masalah-masalah), dan meningkatkan kesehatannya. Penyuluhan dapat mempengaruhi seseorang termasuk juga perilaku seseorang akan pilihan hidup terutama motivasi. penyuluhan berarti bimbingan yang diberikan seseorang terhadap perkembangan orang lain menuju ke arah suatu cita-cita tertentu.

Motivasi keikutsertaan wanita usia subur untuk melakukan pemeriksaan Inspeksi Visual Asam Asetat (IVA) sebelumdilakukan penyuluhan

Berdasarkan hasil ;penelitian setelahpenyuluhan tentang kanker, berdasarkan hasil olah data yang dilakukan, diperoleh rata-rata 62,26 dengan standar deviasi 6,142.

Menurut Amiable dalam Saam (2012) orang yang mempunyai motivasi intrinsik yang tinggi mempunyai ciri-ciri perilaku sebagai berikut: (1) mempunyai rasa ingin tahu yang besar, (2) menyenangi tantangan, (3) ulet/gigih atau tidak mudah putus asa, (4) memandang keberhasilan sebagai usaha, bukan nasib, dan (5) memakai kriteria internal atas kesuksesan atau kegagalan. Artinya, jika sukses orang yang bersangkutan memandang karena usaha dirinya dan jika gagal bukan menyalahkan orang lain tetapi memandang kegagalan tersebut karena diri sendiri.

Sejalan dengan penelitian yang dilakukan olehSepa (2015) dengan judul Pengaruh Penyuluhan Kanker Serviks Terhadap Minat Pemeriksaan IVA Pada Ibu Usia 20-60 Tahun Di Dusun Ngangkrik Triharjo SlemanTahun 2015, diperoleh hasil setelah penyuluhan diberikan minat dalam kategori baik.

Menurut peneliti motivasi merupakan salah satu faktor yang menentukan keberhasilan. Motivasi dapat berfungsi sebagai pendorong. Setiap orang mempunyai motivasi untuk melakukan Pemeriksaan Inspeksi Visual Asam Asetat (IVA), baik itu motivasi dari dalam diri maupun dari luar dirinya. WUS akan bersungguh-sungguh jika memiliki motivasi yang tinggi. Motivasi seorang akan turut menentukan pengetahuan seseorang terhadap Pemeriksaan Inspeksi Visual Asam Asetat (IVA).

\section{Analisa Bivariat}

Pengaruh penyuluhan tentang kanker servikterhadap Pengetahuan pada WUS

Hasil uji statistik didapatkan $t$-test $\rangle \mathrm{t}$ tabel, $25,013>1,780 p$-value $=0,000(p$-value $<a=0,05)$ yang berarti ada Pengaruh penyuluhan tentang kanker servikterhadap Pengetahuan WUS di Wilayah Puskesmas Tanjung Bintang Kecamatan Tanjung Bintang Kabupaten Lampung Selatan Tahun 2019.

Pengetahuan merupakan hasil penginderaan manusia, atau hasil tahu seseorang terhadap objek melalui indera yang dimilikinya (mata, hidung, telinga, dan sebagainya). Orang yang mengadopsi perbuatan dalam diri seseorang tersebut akan terjadi proses kesadaran (Awareness) dimana orang tersebut menyadari dalam arti mengetahui terlebih dahulu terhadap obyek (stimulus), merasa tertarik (Interest) terhadap stimulus atau obyek tertentu (Notoadmotjo, 2012).

Sejalan dengan penelitian yang dilakukan olehRatnasari (2011) dengan judul hubungan penyuluhan tentang kanker serviks dengan pengetahuan dan pelaksanaan IVA Di Puskesmas Ambal I Kabupaten Kebumen. Hasil analisis ada hubungan antara penyuluhan dengan pengetahuan $(p=0,016, O R=2,7)$ dan penelitian yang dilakukan Purwono (2017) efektifitas penyuluhan kesehatan terhadap pengetahuan ibu tentang deteksi dini kanker servik menggunakan metode Inspeksi Visual Asam Asetat (IVA) analisis hasil penelitian menunjukkan pengetahuan responden sebelum diberikan penyuluhan sebesar 59,23 sedangkan pengetahuan sesudah dilakukan penyuluhan adalah sebesar 80,77 dan hasil uji t-test menunjukkan (pvalue $=0,000<0,05$ ).

Menurut pendapat peneliti berdasarkan hasil penelitian diketahui bahwa secara keseluruhan terjadi peningkatan pengetahuan pada ibu yang mengikuti penyuluhan namun dari penelitian ini peningkatan yang didapat tidak semuanya sama, terdapat 5 orang ibu yang mengalami peningkatan sebesar 3-5 point hal ini dapat di sebabkan dari pendidikan ibu yang masih dalam kategori dasar dimana dengan jenjang pendidikan SD-SMP, dengan pekerjaan ibu rumah tangga serta mempunyai anak 2-3 orang sehingga dengan kesibukan ibu sebagai ibu rumah tangga yang mengurus anak, mengurus rumah kemungkinan membuat ibu kurang mendapatkan informasi terkait kanker servik dan kemungkinan di saat diberikan penyuluhan ibu kurang berkonsentrasi karena ada anak yang masih balita.

Pengaruh penyuluhan tentang kanker servikterhadap Motivasi Pemeriksaan IVA pada WUS

Hasil analisis uji bivariat pada table 4.4 diatas, hasil uji statistik didapatkan $t$-test $>t$ tabel, 
$14,353>8,122, p$-value $=0,000$ ( $p$-value $<\alpha=0,05$ ) yang berarti ada Pengaruh penyuluhan tentang kanker servikterhadap Motivasi Pemeriksaan IVA pada WUS di Wilayah Puskesmas Tanjung Bintang Kecamatan Tanjung Bintang Kabupaten Lampung Selatan Tahun 2019.

Penyuluhan kesehatan merupakan gabungan berbagai kegiatan dan kesempatan yang berlandaskan prinsip-prinsip belajar untuk mencapai suatu keadaan, dimana individu, keluarga , kelompok atau masyarakat apa yang dilakukan, secara perorangan maupun secara kelompok dan meminta pertolongan bila perlu (Mubarak, 2012).

Sejalan dengan penelitian yang dilakukan olehRatnasari (2011) dengan judul hubungan penyuluhan tentang kanker serviks dengan motivasi dan pelaksanaan IVA Di Puskesmas Ambal I Kabupaten Kebumen. Hasil analisis ada hubungan antara penyuluhan dengan motivasi $(p=0,016$, $\mathrm{OR}=2,7)$ dan penelitian yang dilakukan Renny (2014) dengan judul pengaruh penyuluhan terhadap motivasi untuk Pemeriksaan Inspeksi Visual Asam Asetat (IVA) di Wilayah Kerja Puskesmas Cisaat Sukabumi, diperoleh hasil terdapat pengaruh peningkatan pada motivasi sebelum dan setelah dilakukan penyuluhan dengan (thitung 6,977 >ttable $1,697 p$-value $=0,000$ ).

Sebaiknya petugas kesehatan agar memberikan konseling yang sangat jelas dan lengkap sehingga dapat diterima dan dimengerti dengan baik oleh wanita Pasangan Usia Subur (PUS). Disarankan agar petugas kesehatan dalam hal usaha preventif pencegahan penyakit kanker serviks, lebih banyak memberikan penyuluhan secara umum dan menyeluruh tentang kanker rahim, tidak hanya himbauan untuk melakukan IVA saja, tetapi lebih menekankan pada informasi tentang apa itu kanker serviks, gejala, penyebab, pencegahan, dan pengobatannya, sehingga WUS dapat menyadari bahwa IVA sangat penting dilakukan.

\section{KESIMPULAN}

Rata-rata pengetahuan ibu sebelum penyuluhan adalah 10,28 dengan standar deviasi 2,224. Rata-rata pengetahuan ibu setelah penyuluhan adalah 17,41 dengan standar deviasi1,773.Rata-rata motivasi ibu sebelum penyuluhan adalah 43,59 dengan standar deviasi 7,556. Rata-rata motivasi ibu setelah penyuluhan adalah62,26 dengan standar deviasi 6,142. Ada Pengaruh penyuluhan tentang kanker servikterhadap Pengetahuan pada WUS di Wilayah Puskesmas Tanjung Bintang Kecamatan Tanjung Bintang Kabupaten Lampung Selatan Tahun
2019Ada Hasil uji statistik didapatkan ( $p$-value = 0,000 ). Ada Pengaruh penyuluhan tentang kanker servikterhadap Motivasi Pemeriksaan IVA pada WUS di Wilayah Puskesmas Tanjung Bintang Kecamatan Tanjung Bintang Kabupaten Lampung Selatan Tahun 2019 ( $p$-value $=0,000)$

\section{SARAN}

Diharapkan manajemen Puskesmas Tanjung Bintang Kecamatan Tanjung Bintang Kabupten Lampung Selatan untuk dapat: Lebih meningkatkan intensitas penyuluhan seperti penyuluhan dilaksanakan $2 x$ dalam sebulan dan diberikan secara rutin oleh petugas kesehatan, dapat di lakukan di Dasa Wisma, PKK dan kumpulan ibu-ibu pengajian. Informasi dapat diberikan dengan cara pemberian leaflet maupun poster-poster yang dibuat dan di pasang di tempat yang mudah terbaca Pada petugas kesehatan agar lebih dapat menggali hal hal yang dapat meningkatkan pengetahuan dan motivasi ibu untuk melakukan Kanker Servik sehingga dapat mendeteksi penyakit pada organ reproduksi sedini mungkin.Diharapkan terdapat kegiatan deteksi dini atau pemeriksaan IVA/ Pap Smear gratis dari pemerintah yang meringankan beban masyarakat, sehingga masyarakat ikut dalam pemeriksaaan. Dapat digunakan sebagai referensi sehingga menambah ilmu pengetahuan tentang keikutsertaan wanita usia subur untuk melakukan pemeriksaan Inspeksi Visual Asam Asetat (IVA)

\section{DAFTAR PUSTAKA}

American Cancer Society. 2018.Cancer Facts and statistickhttp//www.cancer.org diakses tanggal 14 April 2019.

Andari, I. A. A., Sulastri, B., \& Kp, S. 2014. Pengaruh Pendidikan Kesehatan Dan Model Peer Group Terhadap Perilaku Ibu Melakukan Deteksi Dini Kanker Serviks (Doctoral dissertation, Universitas Muhammadiyah Surakarta).

Apriningrum, N., Arya, I. F. D., \& Susanto, H. 2017. Evaluasi Input pada Program Pencegahan Kanker Serviks dengan Pemeriksaan Iva di Kabupaten Karawang. Jurnal Bidan, 3(2), 52-59.

Arikunto.S 2013, Prosedur Penelitian Suatu Pendekatan Praktek, Rineka Cipta Jakarta

Arbyn, M., Sankaranarayanan, R., Muwonge, R., Keita, N., Dolo, A., Mbalawa, C. G.,\& Sharma, A. (2008). Pooled analysis of the accuracy of five cervical cancer screening tests assessed in eleven studies in Africa 
and India. International journal of cancer, 123(1), 153-160.

Arum, Sheria Puspita. 2015. Kanker Serviks. Jakarta: Suka Buku

Budiman \& Riyanto A. 2013. Kapita Selekta Kuisioner Pengetahuan Dan Sikap. Dalam Penelitian Kesehatan. Jakarta : Salemba Medika

Departemen Kesehatan. 2010. Pedomanpelaksanaan-promosi-kesehatan-dipuskesmas.

Dinas Kesehatan Propinsi Lampung, 2017.Profil Kesehatan Propinsi Lampung 2016, Lampung

Dinas Kesehatan Lampung Selatan. 2017. Profil Kesehatan Kabupaten LampungSelatan 2016, Lampung

Hastono, Sutanto Priyo. 2016.Analisis Data Kesehatan . FKM UI Jakarta

Kemenkes, RI. 2015. Buku acuan pencegahan kanker payudara dan kanker leher rahim. Direktorat jendral PP \& PL. Direktorat Pengendalian Penyakit Tidak Menular. Jakarta.

Kemenkes, RI. 2015. Stop Kanker.Pusat data dan informasi

Kemenkes, RI. 2016. Profil kesehatan Indonesia 2015. Jakarta

Kemenkes, RI. 2017. Profil kesehatan Indonesia 2016. Jakarta

Khadijah, Nyanyu. 2014. Psikologi Pendidikan. Nuha Medika: Jakarta

Manuaba, IBG. 2013. IImu Kebidanan, Penyakit Kandungan dan Keluarga Berencana Untuk Pendidikan Bidan. Jakarta: EGC.

Mayrita, S. N., \& Handayani, N. 2014. Hubungan antara paritas dengan kejadian kanker serviks di Yayasan Kanker Wisnuwardhana Surabaya. Journal of Health Sciences, 7(1).

Mulyati, S., Suwarsa, O., \& Arya, I. F. D. 2015. Pengaruh Media Film Terhadap Sikap Ibu Pada Deteksi Dini Kanker Serviks. Jurnal Kesehatan Masyarakat, 11(1), 16-24.

Mubarak. 2012. Promosi Kesehatan Untuk Kebidanan. Jakarta: Salemba Medika

Nursalam. 2016. Manajemen Keperawatan. Jakarta: Salemba Medika

Notoatmodjo, Soekidjo. 2012. Metodologi penelitian kesehatan. Jakarta: Rineka Cipta

Notoatmodjo, Soekidjo. 2012.Promosi Kesehatan dan perilaku kesehatan. Jakarta: Rineka Cipta
Notoatmodjo, Soekidjo. 2012.Kesehatan masyarakat IImu dan Seni. Jakarta: Rineka Cipta

Nugroho. 2010. Kesehatan Wanita gender dan permasalahannya. Yogyakarta: Nuha Medika

Ningrum, R. D., \& Fajarsari, D. 2012. Faktor-Faktor Yang Mempengaruhi Motivasi Ibumengikuti Deteksi Dini Kanker Serviks Melalui Metode Inspeksi Visual Asam Asetat (Iva) Di Kabupaten Banyumas Tahun 2012. Bidan Prada: Jurnal Publikasi Kebidanan Akbid YLPP Purwokerto, 4(01).

Peirson L, Fitzpatrick-Lewis D, Ciliska D, Warren R. 2013. Screening for cervical cancer: a systematic review and meta-analysis. https://www.ncbi.nlm.nih.gov/pubmed/2370 $\underline{6117}$

Peraturan Pemerintah No 61 tahun 2014 tentang Kesehatan Reproduksi,

Ratnasari. 2011. Hubungan penyuluhan tentang kanker serviks dengan pengetahuan dan pelaksanaan IVA Di Puskesmas Ambal I Kabupaten Kebumen

Rasjidi I. 2007. Epidemiologi kanker serviks. Indonesian Jurnal of Cancer

Rizki Mahanani, P., \& Sulastri, S. K. 2016. Pengaruh Pendidikan Kesehatan Terhadap Tingkat Pengetahuan dan Sikap WUS dalam Melakukan Pemeriksaan IVA Di Desa Pabelan (Doctoral dissertation, Universitas Muhammadiyah Surakarta).

Riyanto Agus. 2011. Aplikasi Metodologi Penelitian Kesehatan. Jakarta: Nuha Medika

Saam. 2012. Psikologi Keperawatan. Jakarta: Rajagrafindo Persada

Sawitri, S., \& Sunarsih, S. 2017. Pengaruh Penyuluhan Kanker Serviks terhadap Motivasi Keikutsertaan Wanita Melakukan Pemeriksaan Inspeksi Visual Asam Asetat (IVA). Jurnal Kesehatan, 9(1), 64-69.

Sepa. 2015. Pengaruh Penyuluhan Kanker Serviks Terhadap Minat Pemeriksaan Pap Smear Pada Ibu Usia 20-60 Tahun Di Dusun Ngangkrik Triharjo Sleman Tahun 2015.

Sugiyono. 2017. Metode Penelitian Kuantitatif Kualitatif dan $R \& D$. Bandung:Alfabeta

Susilowati.2014.Pengetahuan Tentang Faktor Risiko, Perilaku Dan Deteksi DiniKanker Serviks Dengan Inspeksi Visual Asam Asetat (Iva)Pada Wanita Di Kecamatan Bogor Tengah, Kota Bogor.

Syafruddin, 2011. Untaian MateriPenyuluhan KIA. Jakarta 
Utami, L. F. Pengaruh Pendidikan Kesehatan Peer Group Terhadap Perilaku Sadari Pada Wanita Usia Produktif Di Dusun Celungan Sumberagung Moyudan Sleman Yogyakarta.

Wiknjosastro, H. 2016,IImu Kebidanan. Yayasan Bina Pustaka Sarwono Prawirohardjo, Jakarta.

Widyastuti, A. D., \& Anjarwati, A. 2013. Pengaruh Penyuluhan tentang Kanker Serviks dengan Metode Peer Group terhadap Minat Ibu Melakukan Pap Smear di Desa Caturharjo Sleman Tahun 2013 (Doctoral dissertation, STIKES'Aisyiyah Yogyakarta). World Health Organization. 2018. Cancer, diambil dari http://www.who.int /cancer/en/index.html1 yang diambil pada 8 Februari 2019. 